\title{
Global versus Country-specific Shocks and International Business Cycles
}

\section{by Michel Normandin and \\ Bruno Powo Fosso}

\author{
Cahier de recherche $n^{\circ}$ IEA-05-07 \\ December 2005
}

ISSN : 0825-8643

Copyright (C) 2005 HEC Montréal.

Tous droits réservés pour tous pays. Toute traduction ou toute reproduction sous quelque forme que ce soit est interdite. Les textes publiés dans la série des Cahiers de recherche HEC n'engagent que la responsabilité de leurs auteurs.

La publication de ce Cahier de recherche a été rendue possible grâce à des subventions d'aide à la publication et à la diffusion de la recherche provenant des fonds de l'École des HEC.

Direction de la recherche, HEC Montréal, 3000, chemin de la Côte-Sainte-Catherine, Montréal (Québec) Canada H3T $2 A 7$. 


\title{
Global versus Country-Specific Shocks and International Business Cycles
}

\author{
Michel Normandin* and Bruno Powo Fosso
}

December 2005

\begin{abstract}
This paper documents the relative importance of global and country-specific shocks for international business cycles. For this purpose, we rely on a symmetric twocountry, dynamic, general-equilibrium model with costly, incomplete, international financial markets. We also relate exogenous technologies and government expenditures to unobservable common and idiosynchratic components, and apply a Kalman filter to extract the associated global and country-specific shocks. We show that the baseline parametrization of the model, including all shocks, closely matches the cyclical fluctuations of key macroeconomic variables for the United States and a non-US aggregate over the post-1975 period. We then experiment alternative parametrizations, isolating the effects of each shock, and find that country-specific technology shocks constitute a prime determinant of international business cycles. Also, global technology shocks have marginal contributions, whereas global and country-specific government-expenditure shocks have negligible effects on cyclical fluctuations.
\end{abstract}

JEL Classification: F32, F41, C32

Keywords: General Equilibrium, Kalman Filter, Symmetric Economies.

* Corresponding Author.

Normandin: Department of Economics and CIRPÉE, HEC Montréal, 3000 Chemin de la Côte-Sainte-Catherine, Montréal Que. H3T 2A7 Canada. Tel.: 514-340-6841. Fax: 514-340-6469. E-mail: michel.normandin@hec.ca. Normandin acknowledges financial support from the Fonds Quebécois de la Recherche sur la Société et la Culture (FQRSC) and Social Science and Humanities Research Council of Canada (SSHRC).

Powo Fosso: Department of Economics and CIRPÉE, HEC Montréal, 3000 Chemin de la Côte-Sainte-Catherine, Montréal Que. H3T 2A7 Canada. Tel.: 514-340-6438. Fax: 514-340-6469. E-mail: bruno.powo-fosso@hec.ca. Powo Fosso acknowledges financial support from the African Economic Research Consortium (AERC).

The authors thank Steve Ambler, Benoît Carmichael, Michael Devereux, Pascal St-Amour, and Désiré Vencatachellum for useful comments. 


\section{Introduction}

It is well recognized that the nature of shocks play a central role on the predictions of international business cycles. In particular, the extent to which a shock is shared or not by different countries constitutes a major determinant of the joint behavior of key macroeconomic variables. For example, intertemporal small-openeconomy models typically predict that favorable global technology shocks lead to increases in output, consumption, and investment, but leave the current account unaffected, whereas favorable country-specific technology shocks produce increases in most macroeconomic variables, but deteriorate the current account (Glick and Rogoff 1995; Iscan 2000). Although not explicitly modelled, the absence of effect of global shocks on the current account relies critically on the notions that economies are symmetric and that the world interest rate adjusts endogeneously. Importantly, the current account is unaffected precisely because identical preferences and technologies across countries imply that the economies react all equally after global shocks, and interest rate adjustments restoring the equilibrium on the world bond market ensure that the current accounts sum to zero over countries.

Moreover, international real-business-cycle models with incomplete financial markets generally predict that technology shocks which moderately spill over international boundaries lead to small cross-country correlations of some macroeconomic variables, and in particular, of consumption (Baxter and Crucini 1995). Although not explicitly decomposed, shocks that greatly spread across boarders mainly act as global shocks, whereas shocks that exhibit moderate international spillovers resemble country-specific shocks. Importantly, cross-country correlations of consumption are small precisely because, under incomplete financial markets, country-specific shocks represent idiosynchratic risks that can be shared across countries only par- 
tially.

Several studies investigate the empirical effects of global and country-specific shocks for the G7 countries. Admittedly, these assessments hinge on the challanging task of disentangling the nature of shocks. A first technique applies structural vector autoregressions to extract global and country-specific shocks by imposing the identification hypothesis that global shocks do not affect the current account (Hoffmann 2001, 2003). Unfortunately, the empirical results appear to be highly sensitive to seemingly minor perturbations of the identification scheme (Nason and Rogers 2002b). A second method constructs global technology shocks from the weighted average of Solow residuals over countries, and measures country-specific shocks as deviations from the cross-country average (Glick and Rogoff 1995). However, the resulting measure of global shocks is likely to capture country-specific movements, given that large fluctuations in Solow residuals in any individual country raise the cross-country average even if the Solow residuals in all other countries remain constant (Gregory and Head 1999). A third approach estimates global and country-specific technology shocks from a specification relating the Solow residuals to unobservable common and idiosynchratic components (Gregory and Head 1999). Under this approach, the relevance of the estimates of shocks obviously depends on the appropriateness of the specification of factor dynamics.

This paper documents the relative importance of global and country-specific shocks for international business cycles. Specifically, we focus on the cyclical fluctuations of key macroeconomic variables for the United States and a non-US aggregate (which includes the non-US G7 countries) over the post-1975 period. For this purpose, we resort to an economic environment which stipulates that countries engage in trade of a single homogenous good (Backus, Kehoe, and Kydland 1992) and of 
one-period bonds (Baxter and Crucini 1995), where trades in the world bond market are costly (Boileau and Normandin 2004). Importantly, this environment offers several advantages. First, it explicitly models the general-equilibrium conditions of symmetric economies. These features are essential to predict that global shocks have no impact on the current account. Second, it leads to endogenous adjustments of interest rates. This feature is relevant for the analysis of large economies, such as the traditional applications for the G7 countries as well as our investigation for the United States and Non-US Aggregate. Third, it involves incomplete financial markets. This feature is required to predict that country-specific shocks produce small cross-country correlations of some macroeconomic variables, and especially of consumption.

We also relate the measures of exogenous technologies and government expenditures for the United States and Non-US Aggregate to unobservable common and idiosynchratic components, which are governed by first-order autoregressive processes (Gregory and Head 1999). We then apply the Kalman filter to extract the associated global and country-specific shocks. This exercise offers a number of advantages. First, it clearly decomposes shocks of different nature. That is, global shocks entirely summarize movements of exogenous variables that spill over international boundaries, whereas country-specific shocks capture all fluctuations that never spread across boarders. Second, it yields, under adequate factor-dynamic specifications, more reliable measures of global and country-specific shocks, compared to those obtained from alternative methods. This is because our measures are not sensitive to the identification scheme, given that they do not rely on the usual arbitrary identification hypotheses. In addition, our measures sharply distinguish global from country-specific shocks, given that fluctuations of an exogenous 
variable of an individual country may be of any magnitude and still be entirely country-specific.

Empirically, we find from the Kalman-filter estimates that, for technology, the global component as well as the US and non-US components systematically increase during recovery episodes and decline during contractionary experiences. This accords with the well-known stylized fact that technology is procyclical for several industrialized countries. The estimates also highlight that, for government expenditures, the global component tends to be acyclical, the US component is procyclical, and the non-US component is countercyclical. Again, this is consistent with the stylized facts documented for the US data and reported for many of the countries included in our Non-US Aggregate. Moreover, applying standard tests indicates that the dynamics of all global and country-specific components are adequately specified by first-order autoregressive processes.

We then show that the economic environment with the baseline parametrization, including all shocks, adequately accounts for the empirical cyclical fluctuations of key macroeconomic variables. In particular, the model closely tracks the conventional statistics (i.e. volatilities, within-country correlations, and cross-country correlations) computed from actual output, consumption, investment, and the current account. We finally document from alternative parametrizations, isolating the effects of each shock, that country-specific technology shocks constitute a prime determinant of international business cycles. That is, these shocks yield statistics that almost always best match the data, produce dynamic responses with the largest magnitudes, and lead to variance decompositions with the largest contributions. In contrast, global technology shocks have marginal contributions, and global and country-specific government-expenditure shocks have negligible effects 
on cyclical fluctuations.

This paper is organized as follows. Section 2 elaborates the model. Section 3 presents the empirical results. Section 4 concludes.

\section{Model}

In this section, we present the economic environment, the process for exogenous variables, as well as the parametrizations. The economic environment relies on a symmetric two-country, dynamic, general-equilibrium model with costly, incomplete, international financial markets. The exogenous-variable process relies on a state-space representation specified to disentangle global and country-specific shocks. Various parametrizations of the exogenous-variable process are designed to extract the effects of global and country-specfic shocks on key macroeconomic variables.

\subsection{Economic Environment}

The home and foreign economy are each populated by a representative consumer, a representative firm, and a government, while an intermediary operates the costly international financial transactions. For expositional purposes, only the home economy is presented, given that the two countries are symmetric (up to stochastic technologies and government expenditures). The foreign-country variables are denoted by an asterisk.

The problem of the consumer is: 


$$
\begin{gathered}
\max _{\left\{C_{t}, N_{t}, K_{t+1}, B_{t+1}\right\}} E_{t} \sum_{j=0}^{\infty} \beta^{j}\left(C_{t+j}-\eta N_{t+j}^{\nu}\right)^{(1-\sigma)} /(1-\sigma), \\
\text { s.t. } \quad C_{t}+I_{t}+T_{t}+q_{t} B_{t+1}=W_{t} N_{t}+r_{t}^{k} K_{t}+B_{t}, \\
K_{t+1}=I_{t}+(1-\delta) K_{t}-\frac{\phi}{2}\left(\frac{I_{t}}{K_{t}}-\delta\right)^{2} K_{t} .
\end{gathered}
$$

The operator $E_{t}$ is the expectation conditional on information available in period $t$. The variable $C_{t}$ denotes consumption, $N_{t}$ is employment, $K_{t}$ is capital, $B_{t}$ represents one-period bonds, $I_{t}$ is investment, $T_{t}$ is taxes, $W_{t}$ is the wage rate, $r_{t}^{k}$ is the rental rate of capital, and $q_{t}$ is the price of bonds. The parameters $\beta$ represents the subjective discount factor, $\sigma$ is the coefficient of relative risk aversion, $1 /(\nu-1)$ is the elasticity of labor supply, $\eta$ is a scale factor, $\phi$ is the adjustment-cost parameter, and $\delta$ is the depreciation rate - where $0<\beta<1, \sigma \geq 1, \nu>1, \eta>0, \phi \geq 0$, and $0<\delta<1$. The preferences (1.1) are adopted to promote a countercyclical current account and reduce the cross-country correlation of consumption (Correia, Neves, and Rebelo 1995; Devereux, Gregory, and Smith 1992). The expression (1.2) depicts the budget constraint. The accumulation of capital (1.3) involves adjustment costs to limit the volatility of investment (Baxter and Crucini 1993).

The problem of the firm is:

$$
\begin{aligned}
& \max _{\left\{N_{t}, K_{t}\right\}} Y_{t}-W_{t} N_{t}-r_{t}^{k} K_{t}, \\
& \text { s.t. } \quad Y_{t}=Z_{t} K_{t}^{\alpha} N_{t}^{1-\alpha} .
\end{aligned}
$$

The variable $Y_{t}$ represents output and $Z_{t}$ is the stochastic, exogenous, level of technology. The parameter $\alpha$ is the share of capital, where $0<\alpha<1$. The expression 
(2.1) defines the profits of the firm. The production function (2.2) exhibits constant return to scale.

The government budget constraint is:

$$
\mathcal{G}_{t}=T_{t}+\omega_{t} \Pi_{t}
$$

The variable $\mathcal{G}_{t}$ corresponds to government expenditures, $\omega_{t}=Y_{t} /\left(Y_{t}+Y_{t}^{*}\right)$ is the home share of world output, and $\Pi_{t}$ is the redistributed profits of the financial intermediary. It is assumed that the domestic and foreign governments own the intermediary, and the ownership shares correspond to the countries' shares of world output. Equation (3) states that the government runs a balanced budget.

Also, the international financial market is operated by a no-entry intermediation sector. The problem of the financial intermediary is:

$$
\begin{aligned}
& \max _{\left\{B_{t+1}, B_{t+1}^{*}\right\}} \Pi_{t}=q_{t} B_{t+1}+q_{t}^{*} B_{t+1}^{*}-B_{t}-B_{t}^{*}-\frac{\varphi}{2}\left(\frac{B_{t+1}^{2}}{Y_{t}}+\frac{B_{t+1}^{* 2}}{Y_{t}^{*}}\right), \\
& \text { s.t. } B_{t+1}+B_{t+1}^{*}=0 .
\end{aligned}
$$

The term $\varphi$ is a transaction-cost parameter, where $\varphi \geq 0$. The profit function (4.1) involves the costs faced by the intermediary in operating international financial transactions. These costs are increasing in the net foreign asset positions of both countries, that is, in the amount of funds handled by the intermediary. The intermediary's costs ensure a unique deterministic steady state, unlike standard incomplete financial-market environments (Boileau and Normandin 2005). In addition, these costs yield a debt-elastic supply of international assets that preserves the 
small cross-country correlations of consumption, obtained from certain incomplete financial-market models (Baxter and Crunini 1995). Equation (4.2) corresponds to the bond-market clearing condition and states that the intermediary lends all funds.

Moreover, the good-market clearing condition is:

$$
C_{t}+C_{t}^{*}+I_{t}+I_{t}^{*}+G_{t}+G_{t}^{*}=Y_{t}+Y_{t}^{*}
$$

The variables $G_{t}=\mathcal{G}_{t}+\omega_{t}(\varphi / 2)\left(B_{t+1}^{2} / Y_{t}+B_{t+1}^{* 2} / Y_{t}^{*}\right)$ and $G_{t}^{*}=\mathcal{G}_{t}^{*}+\omega_{t}^{*}(\varphi / 2)$ $\left(B_{t+1}^{2} / Y_{t}+B_{t+1}^{* 2} / Y_{t}^{*}\right)$ correspond to our notion of stochastic, exogenous, government expenditures. The adjusted government expenditures incorporate the resources lost in operating the international financial market.

\subsection{Exogenous-Variable Process}

Global and country-specific shocks are disentangled from the following statespace representation:

$$
\begin{aligned}
& \left(\begin{array}{c}
z_{t} \\
g_{t} \\
z_{t}^{*} \\
g_{t}^{*}
\end{array}\right)=\left(\begin{array}{cccccc}
1 & 0 & 1 & 0 & 0 & 0 \\
0 & 1 & 0 & 0 & 1 & 0 \\
1 & 0 & 0 & 1 & 0 & 0 \\
0 & 1 & 0 & 0 & 0 & 1
\end{array}\right)\left(\begin{array}{c}
f_{z, t} \\
f_{g, t} \\
v_{z, t} \\
v_{z, t}^{*} \\
v_{g, t} \\
v_{g, t}^{*}
\end{array}\right) \\
& \left(\begin{array}{c}
f_{z, t} \\
f_{g, t} \\
v_{z, t} \\
v_{z, t}^{*} \\
v_{g, t}^{*} \\
v_{g, t}^{*}
\end{array}\right)=\left(\begin{array}{cccccc}
\theta_{z} & 0 & 0 & 0 & 0 & 0 \\
0 & \theta_{g} & 0 & 0 & 0 & 0 \\
0 & 0 & \vartheta_{z} & 0 & 0 & 0 \\
0 & 0 & 0 & \vartheta_{z} & 0 & 0 \\
0 & 0 & 0 & 0 & \vartheta_{g} & 0 \\
0 & 0 & 0 & 0 & 0 & \vartheta_{g}
\end{array}\right)\left(\begin{array}{c}
f_{z, t-1} \\
f_{g, t-1} \\
v_{z, t-1} \\
v_{z, t-1}^{*} \\
v_{g, t-1} \\
v_{g, t-1}^{*}
\end{array}\right)+\left(\begin{array}{c}
\epsilon_{z, t} \\
\epsilon_{g, t} \\
\xi_{z, t} \\
\xi_{z, t}^{*} \\
\xi_{g, t} \\
\xi_{g, t}^{*}
\end{array}\right),
\end{aligned}
$$




$$
\left(\begin{array}{c}
\epsilon_{z, t} \\
\epsilon_{g, t} \\
\xi_{z, t} \\
\xi_{z, t}^{*} \\
\xi_{g, t}^{*} \\
\xi_{g, t}^{*}
\end{array}\right) \sim N I D\left(\left(\begin{array}{l}
0 \\
0 \\
0 \\
0 \\
0 \\
0
\end{array}\right),\left(\begin{array}{cccccc}
\omega_{z}^{2} & 0 & 0 & 0 & 0 & 0 \\
0 & \omega_{g}^{2} & 0 & 0 & 0 & 0 \\
0 & 0 & \nu_{z}^{2} & 0 & 0 & 0 \\
0 & 0 & 0 & \nu_{z}^{2} & 0 & 0 \\
0 & 0 & 0 & 0 & \nu_{g}^{2} & 0 \\
0 & 0 & 0 & 0 & 0 & \nu_{g}^{2}
\end{array}\right)\right)
$$

or more compactly,

$$
\begin{aligned}
\mathbf{w}_{t} & =\mathbf{\Psi} \mathbf{f}_{t}, \\
\mathbf{f}_{t} & =\mathbf{\Theta f}_{t-1}+\mathbf{e}_{t}, \\
\mathbf{e}_{t} & \sim N I D(\mathbf{0}, \boldsymbol{\Omega}) .
\end{aligned}
$$

Here, $z_{t}=\log \left(Z_{t} / Z\right), z_{t}^{*}=\log \left(Z_{t}^{*} / Z\right), g_{t}=\log \left(G_{t} / G\right)$, and $g_{t}^{*}=\log \left(G_{t}^{*} / G\right)$, where $Z$ and $G$ are the steady-state values of technology and governement expenditures. Equation (6.1) is the measurement equation. It relates the measurable variables, $\mathbf{w}_{t}$, to unobservable factors, $\mathbf{f}_{t}$. Equation (6.2) is the transition equation. It specifies the dynamics of the factors. Expression (6.3) describes the distribution of the shocks affecting the factors. It states that the shocks are normally distributed.

The state-space formulation implies that home and foreign technologies, $z_{t}$ and $z_{t}^{*}$, are linked to a common factor, $f_{z, t}$, and to idiosynchratic components, $v_{z, t}$ and $v_{z, t}^{*}$, which are governed by first-order autoregressive $[\mathrm{AR}(1)]$ processes. The common factor and idiosynchratic terms are orthogonal, given that $\Theta$ and $\boldsymbol{\Omega}$ are diagonal matrices. This insures that the commun factor captures a global technology component, whereas each idiosynchratic term corresponds to a country-specific technology component. Moreover, the dynamics of domestic and foreign countryspecific technology components involve identical autocorrelation coefficients, $\vartheta_{z}$, 
and shock variances, $\nu_{z}^{2}$. This is consistent with our symmetric two-country environment. Finally, a similar specification is adopted to decompose government expenditures into global and country-specific components.

The parameters of the exogenous-variable process are estimated by a maximum-likelihood procedure. This procedure first applies the Kalman filter to the specification (6), where the factors are taken as the state. This yields:

$$
\begin{aligned}
\mathbf{u}_{t / t-1} & =\mathbf{w}_{t}-E_{t-1} \mathbf{w}_{t}=\mathbf{w}_{t}-\boldsymbol{\Psi} \mathbf{f}_{t / t-1}, \\
\boldsymbol{\Sigma}_{t / t-1} & =E_{t-1}\left(\mathbf{u}_{t} \mathbf{u}_{t}^{\prime}\right)=\boldsymbol{\Psi} \boldsymbol{\Lambda}_{t / t-1} \Psi^{\prime} \\
\mathbf{f}_{t / t-1} & =E_{t-1}\left(\mathbf{f}_{t}\right)=\boldsymbol{\Theta} \mathbf{f}_{t-1 / t-1}, \\
\boldsymbol{\Lambda}_{t / t-1} & =E_{t-1}\left(\mathbf{f}_{t} \mathbf{f}_{t}^{\prime}\right)=\boldsymbol{\Theta} \boldsymbol{\Lambda}_{t-1 / t-1} \boldsymbol{\Theta}^{\prime}+\boldsymbol{\Omega}, \\
\mathbf{f}_{t / t} & =E_{t}\left(\mathbf{f}_{t}\right)=\mathbf{f}_{t / t-1}+\boldsymbol{\Lambda}_{t / t-1} \boldsymbol{\Psi}^{\prime} \boldsymbol{\Sigma}_{t / t-1}^{-1} \mathbf{u}_{t / t-1}, \\
\boldsymbol{\Lambda}_{t / t} & =E_{t}\left(\mathbf{f}_{t} \mathbf{f}_{t}^{\prime}\right)=\boldsymbol{\Lambda}_{t / t-1}-\boldsymbol{\Lambda}_{t / t-1} \boldsymbol{\Psi}^{\prime} \boldsymbol{\Sigma}_{t / t-1}^{-1} \boldsymbol{\Psi} \boldsymbol{\Lambda}_{t / t-1} .
\end{aligned}
$$

Equations (7.1) and (7.2) are related to the prediction errors of the measurable variables. Formulae (7.3) and (7.4) correspond to the prediction equations of the factors. Expressions (7.5) and (7.6) represent the updating equations of the factors when an additional observation becomes available.

The formulae (7) are evaluated recursively for $t=1, \ldots, T$. For this purpose, we use the unconditional moments to initialize $\mathbf{f}_{0 / 0}=\mathbf{0}$ and $\operatorname{vec}\left(\boldsymbol{\Lambda}_{0 / 0}\right)=(\mathbf{I}-$ $\boldsymbol{\Theta} \otimes \boldsymbol{\Theta})^{-1} \operatorname{vec}(\boldsymbol{\Omega})$, where $I$ is the identity matrix, vec is the vectorization operator and $\otimes$ is the Kronecker product. Also, we give values to the parameter vector $\boldsymbol{\Gamma}$, where $\boldsymbol{\Gamma}$ comprises all the unconstrained elements of $\boldsymbol{\Theta}$ and $\boldsymbol{\Omega}$. Note that equation (7.5) provides the best (in the conditional mean square error sense) estimates of 
the factors (Sentana 2004). These estimates are useful to extract the global and country-specific components.

The Kalman filter is then used to construct the log-likelihood of the sample (ignoring the constant term) associated with conditionally Gaussian components:

$$
L(\mathbf{u}, \boldsymbol{\Gamma})=-\frac{1}{2} \sum_{t=1}^{T} \log \left|\Sigma_{t / t-1}\right|-\frac{1}{2} \sum_{t=1}^{T} \mathbf{u}_{t / t-1}^{\prime} \Sigma_{t / t-1}^{-1} \mathbf{u}_{t / t-1}
$$

The estimates are obtained by maximizing (8) over the parameters $\boldsymbol{\Gamma}$. To this end, we use the BHHH algorithm.

This estimation exercise is performed for quarterly fluctuations, at the business cycle frequency, covering the post-1975 period for the United States and an aggregate of non-US countries (see the Appendix). The non-US countries are Australia, Canada, Finland, France, Germany, Italy, Japan, and the United Kingdom. These countries are often considered in international real-business-cycle studies (e.g. Backus, Kehoe, and Kydland 1994), current-account studies (e.g. Glick and Rogoff 1995), and interest-differential studies (e.g. Lane and Milesi-Ferretti 2002). In addition, the United States and the Non-US Aggregate are of similar sizes, which is in line with our symmetric two-country environment.

The maximum-likelihood estimates (standard errors) are $\theta_{z}=0.823(0.098)$, $\theta_{g}=0.758$ (1.090), $\vartheta_{z}=0.756(0.068), \vartheta_{g}=0.755(0.051), \omega_{z}=0.004$ (0.001) $\omega_{g}=0.001(0.001), \nu_{z}=0.007$ (0.001), and $\nu_{g}=0.007$ (0.001). These estimates reveal that the autocorrelation coefficients are similar for all global and countryspecific components. This implies that the various components exhibit similar degrees of persitence. Also, the estimates indicate that the standard deviation is the 
smallest for global government-expenditure shocks, followed by global technology shocks, and by country-specific shocks. This implies that the global governmentexpenditure component is the smoothest, followed by the global technology component, and by the country-specific components. These features are confirmed by a visual inspection of the Kalman-filter estimates of the global and country-specific components (Figure 1).

To gain confidence in our estimated components, we verify whether they exhibit the cyclical properties documented for technology and government expenditures (Figure 1). For technology, the global component as well as the US and non-US components systematically increase during recovery episodes, and decline during contractionary experiences. Importantly, this observation is consistent with procyclical technology, as documented for the United States and for all the countries included in our Non-US Aggregate (Backus, Kehoe, and Kydland 1995). For government expenditures, the US component generally increases more in recoveries than in contractions. Interestingly, this feature is in line with procyclical government expenditures (Backus, Kehoe, and Kydland 1995), strong positive dynamic responses of output following unanticipated expansionary budget policies (Perotti 2004), and pronounced cyclical ratcheting effects (Hercowitz and Strawczynski 2004) found for the United States. The ratcheting effects occur when high tax revenues in expansions make it difficult for governments to resist pressure from interest groups to reduce spendings. In contrast, the non-US government-expenditure component increases more in contractions. This accords with the countercyclical government expenditures reported for many of the countries included in our Non-US Aggregate (Backus, Kehoe, and Kydland 1995), strong negative dynamic responses of output after unexpected expansionary budget policies for some countries of the Non-US 
Aggregate (Perotti 2004), and insignificant cyclical ratcheting effects reported for all our non-US countries, except Canada and Japan (Hercowitz and Strawczynski 2004).

For completeness, we compare our Kalman-filter estimates of components to those obtained from two popular methods (Figure 1). The first alternative method (labelled Average) constructs global components from the averages of the exogenous-variable observations for the United States and the Non-US Aggregate, and measures country-specific components as deviations from the averages. Importantly, the Average-method yields estimates of global technology and governmentexpenditure components that are more volatile than those found from the Kalman filter. Also, the Average-method produces estimates of country-specific technology and government-expenditure components that are less volatile than those obtained from the Kalman filter. These results accord with the notion that the Averagemethod is likely to yield measures of global components that capture countryspecific movements. The second alternative method (labelled SVAR) applies structural vector autoregression processes to identify global shocks from the hypothesis that these shocks do not contemporaneously affect the current account. The approach then uses the processes to recursively construct global components as the exogenous-variable values prevailling when only global shocks occur, and measures country-specific components as deviations from the global components. This time, the SVAR-method leads to estimates of global technology and governmentexpenditure components that are less volatile than those found from the Kalman filter. Also, the SVAR-method produces estimates of country-specific technology and government-expenditure components that are more volatile than those obtained from the Kalman filter. In addition, the SVAR-method yields a non-US 
government-expenditure component that becomes procyclical. This finding is at odd with facts.

Finally, the Kalman-filter estimates rely on dynamics that seem adequately specified by the $\mathrm{AR}(1)$ processes of the transition equation (6.2) for all global and country-specific components. That is, using Lagrange Multiplier tests we can never reject the hypothesis that the coefficients affecting higher order lags (up to 8 lags) are jointly null.

\subsection{Parametrizations}

The model does not possess an analytical solution for general values of the underlying parameters. We approximate the solution by linearizing the equations characterizing the equilibrium around the deterministic steady state, and by solving the resulting system of difference equations for given values of parameters (King, Plosser, and Rebelo 2002). The deterministic steady state is unique and the linear system of difference equations is stationary because of the intermediary's costs. Also, identical systems of difference equations are obtained for the following cases: (i) private ownerships (rather than public ownerships) of the financial intermediary with fixed costs that eliminate profits, (ii) losses of output in production (rather than adjustment of government expenditures) capturing the intermediary's resources lost in operating the international financial market, and (iii) alternative redistributions of the intermediary's profits and of resource losses across domestic and foreign governments (Boileau and Normandin 2004).

To explain our baseline parametrization, we divide the parameters in three sets. The first set relies on values used in previous studies. That is, we fix $\beta=0.99$, 
$\alpha=0.36, \delta=0.025$, and $\eta=3.24$ so that the steady state of employment is 30 percent of the time endowment (Backus, Kehoe, and Kydland 1992). Also, we set $\sigma=2$ and $1 /(\nu-1)=1.43$ (Greenwood, Hercowitz, and Huffman 1988; Correia, Neves, and Rebelo 1995). Finally, we fix $\varphi / \beta^{2}=0.0035$ to accord with values used for the debt-interest rate elasticity (Nason and Rogers 2002a).

The second set of parameters is selected to match actual statistics for the United States. For example, we set $G / Y=0.163$ to the average sample output share of government expenditures in the United States. Moreover, we fix $\phi=3.20$ to match the relative volatility of investment in the United States.

The last set of parameters is related to the maximum-likelihood estimates of the exogenous-variable process. More explicitly, our baseline parametrization sets all parameters of (6) to their correspondings estimates. This implies that the baseline parametrization involves all shocks, i.e. global as well as country-specific technology and government-expenditure shocks. Note that this parametrization represents a useful starting point to verify whether our economic environment explains adequately the cyclical fluctuations found in the data for key macroeconomic variables.

We also use alternative parametrizations to isolate the effects of each shock. For example, we extract global technology shocks by using identical values than those for the baseline parametrization, except that we impose $E\left(\epsilon_{g, t}^{2}\right)=\omega_{g}^{2}=0$, $E\left(\xi_{z, t}^{2}\right)=E\left(\xi_{z, t}^{*}{ }^{2}\right)=\nu_{z}^{2}=0$, and $E\left(\xi_{g, t}^{2}\right)=E\left(\xi_{g, t}^{*}{ }^{2}\right)=\nu_{g}^{2}=0$. Likewise, global government-expenditure shocks are obtained from the restrictions $E\left(\epsilon_{z, t}^{2}\right)=\omega_{z}^{2}=0$, $E\left(\xi_{z, t}^{2}\right)=E\left(\xi_{z, t}^{*}{ }^{2}\right)=\nu_{z}^{2}=0$, and $E\left(\xi_{g, t}^{2}\right)=E\left(\xi_{g, t}^{*}{ }^{2}\right)=\nu_{g}^{2}=0$. Moreover, countryspecific (i.e. domestic and foreign) technology shocks are obtained from $E\left(\epsilon_{z, t}^{2}\right)=$ 
$\omega_{z}^{2}=0, E\left(\epsilon_{g, t}^{2}\right)=\omega_{g}^{2}=0$, and $E\left(\xi_{g, t}^{2}\right)=E\left(\xi_{g, t}^{*}{ }^{2}\right)=\nu_{g}^{2}=0$. Also, domestic technology shocks are isolated by further imposing that $\mathrm{E}\left(\xi_{z, t}^{*}\right)=\nu_{z}^{2}=0$, whereas foreign technology shocks require the restriction $\mathrm{E}\left(\xi_{z, t}^{2}\right)=\nu_{z}^{2}=0$. Similarly, countryspecific (i.e. domestic and foreign) government-expenditure shocks are obtained from $E\left(\epsilon_{z, t}^{2}\right)=\omega_{z}^{2}=0, E\left(\epsilon_{g, t}^{2}\right)=\omega_{g}^{2}=0$, and $E\left(\xi_{z, t}^{2}\right)=E\left(\xi_{z, t}^{*}{ }^{2}\right)=\nu_{z}^{2}=0$. Finally, domestic government-expenditure shocks are isolated by further imposing that $\mathrm{E}\left(\xi_{g, t}^{*}{ }^{2}\right)=\nu_{g}^{2}=0$, whereas foreign government-expenditure shocks require the restriction $\mathrm{E}\left(\xi_{g, t}^{2}\right)=\nu_{g}^{2}=0$.

\section{Results}

In this section, we confront the predictions of the economic environment with the baseline parametrization to the salient empirical features characterizing the cyclical fluctuations of key macroeconomic variables. This exercise is performed to verify that our model involving all global and country-specific shocks provides an adequate description of the data. We then compare the predictions generated from the baseline parametrization to those obtained from the alternative parametrizations. This exercise is performed to isolate the effects of global shocks from those of country-specific shocks.

\subsection{Baseline}

As a useful starting point, we challenge the predictions of the model to the empirical cyclical fluctuations. In what follows, output $\left(y_{t}\right)$, consumption $\left(c_{t}\right)$, investement $\left(i_{t}\right)$, and the current account $\left(x_{t}\right)$ refer to the cyclical fluctuations of the logarithm of the real gross domestic product, the logarithm of real private final consumption, the logarithm of real fixed capital formation, and the ratio of the real 
current account to real gross domestic product. Occasionnally, the current account $\left(x_{t}\right)$ is further decomposed into the rate of national saving $\left(s_{t} / y_{t}\right)$ and the rate of investment $\left(i_{t} / y_{t}\right)$. The saving rate $\left(s_{t} / y_{t}\right)$ refers to the cyclical fluctuations of the ratio of the real current account plus real fixed capital formation to real gross domestic product, whereas the investment rate $\left(i_{t} / y_{t}\right)$ refers to the cyclical fluctuations of the ratio of real fixed capital formation to real gross domestic product. As is standard practice, the empirical cyclical fluctuations of a variable are measured by the deviations from the trend extracted by the HP filter with a smoothing parameter of 1,600 (Hodrick and Prescott 1997). Also, the predicted cyclical fluctuations of a variable are measured by the deviations from the deterministic steady state.

Table 1 confronts the empirical and predicted statistics. To do so, we formally verify that the difference between the empirical and predicted statistics is null using a $\chi^{2}(1)$ test, where this test accounts for the uncertainty associated with the estimated parameters of the exogenous-variable process. The empirical statistics are computed from the sample estimates of the cyclical fluctuations for the United States, the Non-US Aggregate, and the 10-Country Average. As mentioned above, the United States and the Non-US Aggregate are of similar sizes, and as such are in line with our symmetric two-country environment. The 10-Country Average refers to the means of the sample estimates over all 10 countries, and as such constitutes a useful summary of individual countries. The predicted statistics are computed from the economic environment with the baseline parametrization, which includes all global and country-specific shocks. The statistics are the relative volatility, the within-country correlation, and the cross-country correlation. The relative volatility corresponds to the ratio of the standard deviation of a variable to the standard deviation of output. The within-country correlation is the contemporaneous corre- 
lation between variables of the same country. The cross-country correlation is the contemporaneous correlation between variables of different countries.

First, the economic environment with the baseline parametrization correctly predicts that consumption and the current account are less volatile than output, and that investment is more volatile than output. More explicitly, the predicted relative volatility of consumption is 0.94 , while the empirical relative volatilities $(p$ values) are 0.88 (0.03) for the United States, 0.85 (0.01) for the Non-US Aggregate, and 0.90 (0.11) for the 10-Country Average. Also, the predicted relative volatility of the current account is 0.25 , and the empirical relative volatilities ( $p$-values) are 0.30 (0.73) for the United States, 0.49 (0.11) for the Non-US Aggregate, and 0.62 (0.02) for the 10-Country Average. Finally, the predicted relative volatility of investment is 2.32 , while the empirical relative volatilities ( $p$-values) are $2.32(0.99)$ for the United States, 2.62 (0.47) for the Non-US Aggregate, and 2.59 (0.52) for the 10-Country Average.

Second, the model adequately predicts that consumption and investment are procyclical, that the current account is countercyclical, and that the saving and investment rates are positively correlated. That is, the predicted correlation between consumption and output is 0.98 , while the empirical correlations ( $p$-values) are 0.91 (0.03) for the United States, 0.87 (0.01) for the Non-US Aggregate, and 0.79 (0.00) for the 10-Country Average. The predicted correlation between investment and output is 0.87 , and the empirical correlations ( $p$-values) are $0.92(0.59)$ for the United States, 0.79 (0.24) for the Non-US Aggregate, and 0.74 (0.07) for the 10-Country Average. Also, the predicted correlation between the current account and output is -0.28 , while the empirical correlations ( $p$-values) are $-0.48(0.02)$ for the United States, -0.28 (0.93) for the Non-US Aggregate, and -0.25 (0.51) for the 
10-Country Average. Finally, the predicted correlation between the saving and investment rates is 0.71 , and the empirical correlations ( $p$-values) are $0.43(0.04)$ for the United States, 0.39 (0.02) for the Non-US Aggregate, and 0.30 (0.00) for the 10-Country Average.

Third, the model appropriately predicts that consumptions at home and abroad and that outputs at home and abroad are positively correlated, where the correlations of consumptions and of outputs across countries are about the same size. More precisely, the predicted correlation between consumptions at home and abroad is 0.32 , while the empirical correlations ( $p$-values) are $0.20(0.70)$ for the Non-US Aggregate and 0.17 (0.63) for the 10-Country Average. Also, the predicted correlation between outputs at home and abroad is 0.28 , while the empirical correlations ( $p$-values) are 0.38 (0.73) for the Non-US Aggregate and $0.29(0.98)$ for the 10-Country Average.

Overall, the economic environment with the baseline parametrization adequately accounts for the empirical cyclical fluctuations. In particular, the model closely matches the relative volatilities, the within-country correlations, and the cross-country correlations of the various macroeconomic variables.

\subsection{Global Shocks}

Table 2 presents the statistics predicted from the baseline parametrization and from the alternative parametrizations involving only global shocks. These statistics are useful to detect which predictions deviate severely from those of the baseline parametrization. These cases are refered to as anomalies, given that the predictions obtained from the baseline parametrization closely match the data. Fig- 
ure 2 displays the dynamic responses of the macroeconomic variables to positive one standard-deviation global shocks. These responses are useful to highlight the economic factors leading to anomalies. Table 3 reports the variance decompositions of forecast errors associated with the various macroeconomic variables. These decompositions are useful to document the relative importance of each shock.

The statistics generated from the baseline parametrization and exclusively from global technology shocks are sometimes numerically very close. In particular, the volatility of consumption relative to that of output and the correlation between consumption and output are almost identical across the two parametrizations. Unfortunately, the statistics also present several anomalies. For example, the current account now displays no volatility at all. Also, the saving and investment rates, consumptions at home and abroad, as well as outputs at home and abroad become perfectly positively correlated.

The dynamic responses indicate that an increase in global technology has a number of effects on the variables at home. First, it raises ouput following the gains in productivity. Second, it raises investment given the improvements in the marginal product of capital. Third, it raises both consumption and saving because of positive wealth effects. Fourth, it does not affect the current account since the investment boom is fully funded by the national saving. This occurs because global technology shocks have identical effects on domestic and foreign variables, given that the two countries are symmetric economies. Thus, the prices of bonds (or synonymously, the reciprocal of interest rates) adjust to clear the bond market (as well as the goods market) in such a way that it precludes any international lending and borrowing. Importantly, this general-equilibrium result is predicted by our model, rather than imposed a priori. 
The responses hint at prominent predicted features and provide intuition behind the anomalies documented above. First, the responses of consumption are smaller than those of output, whereas the responses of investment are larger, and the responses of the current account are null. This suggests that consumption is less volatile than output, whereas investment is more volatile, and the current account exhibits no volatility at all. Second, the responses of consumption, investment, and output are always positive. This suggests that consumption and investment are procyclical. Third, the responses of the saving and investment rates are identical, the responses of consumptions at home and abroad are the same, and those of outputs at home and abroad are equal. This suggests that these three pairs of variables are perfectly positively correlated.

The responses are numerically sizeable for all macroeconomic variables, except for the current account. This mainly occurs because global technology shocks are sizeable, as revealed by the estimate of their standard deviation. Importantly, the magnitudes of the responses suggest that output, consumption, and investment are affected by global technology shocks. Intuition suggests that this arises because the pronounced cyclical fluctuations of macroeconomic variables are partially induced by the fairly volatile global technology component, which is generated from the sizeable shocks (Figure 1).

The variance decompositions of forecast errors further indicate that the various macroeconomic variables are differently affected by global technology shocks. Specifically, these shocks have sizeable contributions for output and consumption, modest contributions for investment, and no contributions at all for the current account. These contributions suggest that global technology shocks constitute a nonnegligible determinant for output and consumption. As a result, these shocks 
lead to an appropriate volatility of consumption relative to that of output and an adequate correlation between consumption and output.

In contrast, the statistics generated from the baseline parametrization and exclusively from global government-expenditure shocks are almost always substantially different. For example, consumption becomes more volatile than output. In addition, the current account displays no volatility, while the saving and investment rates, consumptions at home and abroad, as well as outputs at home and abroad are perfectly positively correlated.

The dynamic responses indicate that an increase in global government expenditures has two main effects on the variables at home. First, it reduces output, consumption, saving, and investment since it acts as a resource drain, and thus, it generates negative wealth effects. Second, it does not affect the current account since the declines in investment and national saving are of identical magnitudes. Again, this arises because global shocks have identical effects on domestic and foreign variables, so that the adjustment of the prices of bonds precludes any international lending and borrowing.

The responses indicate the economic factors leading to anomalies. First, the responses (in absolute values) of consumption are larger than those of output, whereas the responses of the current account are null. This suggests that consumption is more volatile than output, whereas the current account displays no volatility. Second, the responses of the saving and investment rates are identical, the responses of consumptions at home and abroad are the same, and those of outputs at home and abroad are equal. This suggests that these three pairs of variables are perfectly positively correlated. 
The responses are very small for all macroeconomic variables. This occurs because global government-expenditure shocks are small. Also, the magnitudes of the responses suggest that all variables are almost completely unaffected by global government-expenditure shocks. This is because the cyclical fluctuations of macroeconomic variables are unrelated to the smooth global government-expenditure component (Figure 1).

The variance decompositions of forecast errors confirm that the macroeconomic variables are systematically unaffected by global government-expenditure shocks. This implies that global government-expenditure shocks represent an unimportant element for the determination of the variables. As a result, these shocks lead to inappropriate statistics.

\subsection{Country-Specific Shocks}

Table 4 reports the statistics predicted from the baseline parametrization and from the alternative parametrizations involving only country-specific shocks. Figure 3 displays the dynamic responses of the macroeconomic variables to positive one standard-deviation country-specific technology shocks. Figure 4 shows the responses to positive one standard-deviation country-specific government-expenditure shocks. Table 5 presents the variance decompositions of forecast errors associated with the macroeconomic variables.

The statistics generated from the baseline parametrization and exclusively from country-specific (i.e. domestic and foreign) technology shocks are almost always numerically very close. In fact, the statistics exhibit only two anomalies. That is, consumptions at home and abroad as well as outputs at home and abroad be- 
come negatively correlated. Also, the statistics calculated exclusively from domestic technology shocks display the same problems. However, the statistics obtained exclusively from foreign technology shocks feature several additional anomalies. For example, the current account is now more volatile than output, the current account becomes procyclical, while the saving and investment rates are negatively correlated.

The dynamic responses show that an increase in domestic technology has similar effects on most variables at home than those associated with an increase in global technology. Namely, it raises output, investment, consumption, and saving. This time, however, it deteriorates the current account because the national saving does not rise enough to fully fund the investment boom. This occurs because domestic technology shocks have different effects on domestic and foreign variables, even if the two countries are symmetric economies. In particular, an increase in domestic technology reduces consumption and output abroad because it induces much smaller wealth effects abroad than at home. The difference in these wealth effects arises because the incomplete financial markets in our model preclude perfect risk sharing.

These responses highlight key predictions as well as some anomalies. First, the responses of consumption and of the current account are smaller than those of output, whereas the responses of investment are larger. This suggests that consumption and the current account are less volatile than output, whereas investment is more volatile. Second, the responses of consumption, investment, and output are always positive, whereas the responses of the current account are generally negative. This suggests that consumption and investment are procyclical, whereas the current account is countercyclical. Third, the responses of the saving and invest- 
ment rates are most of the time positive, while the responses of consumptions at home and abroad as well as those of outputs at home and abroad are of opposite signs. This suggests that the saving and investment rates are positively correlated, while consumptions at home and abroad as well as outputs at home and abroad are negatively correlated.

The dynamic responses also indicate the effects of an increase in foreign technology. These responses provide intuitions for the following anomalies. First, the responses (in absolute values) of the current account are larger than those of output. This suggests that the current account is more volatile than output. Second, the responses of the current account are initially positive and become eventually negative, whereas the responses of output are always negative. This suggests that the current account is procyclical. Third, the responses of the saving rate are always negative, while those of the investment rate are initially negative and eventually positive. This suggests that the saving and investment rates are negatively correlated.

The responses are numerically much larger for all domestic variables following domestic technology shocks than after foreign technology shocks, except for the current account. This occurs despite the fact that both domestic and foreign technology shocks are large, as measured by the estimates of their standard deviations. Importantly, the magnitudes of the responses suggest that output, consumption, and investment are mainly affected by domestic technology shocks, whereas the current account is equally affected by domestic and foreign technology shocks. This suggests that the pronounced cyclical fluctuations of most domestic variables are intimatetly related to the volatile domestic technology component, which is generated from large shocks (Figure 1). 
The variance decompositions of forecast errors confirm that the macroeconomic variables are differently affected by domestic and foreign technology shocks. Specifically, domestic technology shocks have substantial contributions for output, consumption, investment, and the current account. In contrast, foreign technology shocks have negligible contributions for output and consumption, modest contributions for investment, and substantial contributions for the current account. These contributions suggest that domestic technology shocks constitute a prime determinant for all domestic variables. As a result, these shocks lead to appropriate relative volatilities of consumption, investment, and the current account and to adequate correlations between each of these variables and output. In addition, foreign technology shocks also represent a nonnegligible determinant of the current account. That is, combining domestic technology shocks to the foreign ones reduces the relative volatility and accentuates the countercyclicality of the current account. As a result, this brings the statististics of the current account closer to those generated from the baseline parametrization.

Unfortunately, the statistics generated from the baseline parametrization and exclusively from country-specific (i.e. domestic and foreign) governmentexpenditure shocks are almost always substantially different. In particular, consumption is more volatile than output and the saving and investment rates are almost perfectly positively correlated. Also, the statistics obtained exclusively from domestic government-expenditure shocks display similar problems. Finally, the statistics associated exclusively with foreign government-expenditure shocks depict other anomalies. This time, the current account becomes procyclical, while the saving and investment rates are almost perfectly positively correlated.

The dynamic responses show that an increase in domestic government ex- 
penditures has similar effects on most variables at home than those associated with an increase in global government expenditures. In particular, it reduces output, consumption, saving, and investment. However, it slightly improves the current account because the decline of the national saving is slightly less pronounced than that of investment. Again, this arises because domestic shocks have different effects on domestic and foreign variables. In particular, the decline of consumption and output at home are more accentuated than those abroad, because the wealth effects across countries lead to imperfect risk sharing.

These responses lead to the following anomalies. First, the responses (in absolute values) of consumption are larger than those of output. This suggests that consumption is more volatile than output. Second, the responses of the saving and investment rates are almost the same. This suggests that this pair of variables is almost perfectly positively correlated.

The dynamic responses also indicate the effects of an increase in foreign government expenditures. These responses reflect the following anomalies. First, the responses of the current account and of output are always slightly negative. This suggests that the current account is procyclical. Second, the responses of the saving and investment rates are always negative and of similar magnitudes. This suggests that these two variables are almost perfectly positively correlated.

The responses are very small for all macroeconomic variables following domestic and foreign government-expenditure shocks. This arises despite the fact that both domestic and foreign government-expenditure shocks are large. Also, the magnitudes of the responses suggest that all variables are almost completely unaffected by country-specific government-expenditure shocks. This indicates that the cycli- 
cal fluctuations of macroeconomic variables bear little relations with the volatile country-specific government-expenditure components.

The variance decompositions of forecast errors confirm that the macroeconomic variables are systematically unaffected by domestic and foreign governmentexpenditure shocks. This implies that country-specific government-expenditure shocks represent an unimportant factor for the determination of the variables. As a result, these shocks lead to inappropriate statistics.

Overall, our findings show that domestic technology shocks constitute a prime determinant of international business cycles. That is, these shocks yield statistics displaying almost always the best match with those generated from the baseline parametrization, produce dynamic responses exhibiting the largest magnitudes, and lead to variance decompositions with the largest contributions. More precisely, domestic technology shocks represent a central factor of the volatilities of consumption and investment and of their covolatilities with output. Also, combining these shocks to the foreign ones reduces the volatility and accentuates the countercyclicality of the current account, to bring these statistics closer to those obtained from the baseline parametrization. Likewise, combining domestic technology shocks to the global ones reduces the cross-country correlations of output and consumption, to bring these statistics closer to the data. Finally, global and country-specific government-expenditure shocks have negligible effects on cyclical fluctuations.

\section{Conclusion}

This paper has documented that country-specific technology shocks consti- 
tute a prime determinant of the cyclical fluctuations of key macroeconomic variables for the United States and a non-US aggregate over the post-1975 period. Specifically, these shocks yield statistics that almost always best match the data, produce dynamic responses with the largest magnitudes, and lead to variance decompositions with the largest contributions. In contrast, global technology shocks have marginal contributions, and global and country-specific government-expenditure shocks have negligible effects on cyclical fluctuations.

These findings are obtained from a general-equilibrium environment involving symmetric economies. This environment is intentionally adopted because it predicts (rather than imposes, as in previous studies) that global shocks have no effect on the current account. Future research, however, could relax the assumption stipulating that the economies are symmetric. In particular, country-specific components and global shocks could exhibit different persistence degrees and sizes across economies. These features would be in line with the empirical results suggesting that US technology shocks diffuse intantaneously to European countries and Japan (Elliott and Fatas 1996) and are closely related to global technology shocks (Gregory and Head 1999). 


\section{Appendix A}

The quarterly seasonally adjusted measures are constructed for 10 developed countries and an aggregate of non-US countries over the post-1975 period. The measures are computed from the International Financial Statistics (IFS) released by the International Monetary Funds, as well as the Main Economic Indicators (MEI) and the Quarterly National Accounts (QNA) published by the Organization for Economic Cooperation and Development. The individual countries (common samples for all measures) are Australia (1975-I to 2001-II), Austria (1975-I to 1998-IV), Canada (1975-I to 2001-II), Finland (1978-I to 2001-II), France (1975-I to 1999-I), Germany (1975-I to 2001-II), Italy (1975-I to 2001-II), Japan (1977-I to 2001-II), the United Kingdom (1975-I to 2001-II), and the United States (1975-I to 2001-II). Germany refers to West Germany and Unified Germany for the pre- and post-1990 periods. As a group, these countries account for 55 percent of the overall 1990 real gross domestic product of the 116 countries for which data are available in the Penn World Tables (Mark 5.6a).

The Non-US Aggregate covers the 1975-I to 2001-II period. On average, the United States and Non-US Aggregate account for 43 and 57 percents of the 10-country output in our data. Thus, the United States and the Non-US Aggregate represent two entities of similar sizes.

\section{A.1 Output}

For each country, output is measured by the weighted nominal gross domestic product (GDP) in national currency (source: QNA), deflated by the all-item consumer price index (CPI) for the baseyear 1995 (source: MEI). The output weights are country-specific constants that convert the values of output to comparable units (Backus, Kehoe, and Kydland 1992). The constants are chosen to match the averages of our quarterly values of output in 1985 to the yearly data on real GDP obtained from international prices for 1985 (source: Summers and Heston 1988, variables 1 and 2, Table 3). The published data for Germany and Austria are not seasonally adjusted. Thus, German and Austrian output is regressed (by OLS) on quarter dummies to remove seasonality. For the Non-US Aggregate, output is constructed by summing over all countries, except the United States. For each country 
and the Non-US Aggregate, the measure of empirical fluctuations, at the business cycle frequency, is obtained by detrending the logarithm of output from the HP filter with a smoothing parameter of 1,600 (Hodrick and Prescott 1997).

\section{A.2 Current Account}

For each country, the current account is the product of the ouput weight, the nominal current account in US dollars (source: IFS), and the nominal exchange rate of national currency units per US dollar (source: IFS), divided by the CPI. The current account is further regressed on quarter dummies to remove seasonality. For the Non-US Aggregate, the current account is constructed by summing over all countries, except the United States. In doing so, the few missing values for Japan (from 1975-I to 1976-IV) are replaced by zeros. As hoped, the current account to output ratios for the United States and the Non-US Aggregate mirror each other well (i.e. the correlation is -0.70). For each country and the Non-US Aggregate, the cyclical fluctuations are extracted by detrending the current account to output ratio from the HP filter.

\section{A.3 Consumption, Investment, and Government Expenditures}

For each country, consumption is the output weight times nominal private final consumption expenditures in national currency (source: QNA), deflated by the CPI. Investment is the output weight times nominal gross fixed capital formation in national currency (source: QNA), deflated by the CPI. Government expenditures are the output weight times nominal government final consumption expenditures in national currency (source: QNA), normalized by the CPI. For consumption, investment, and government expenditures, German and Austrian data are regressed on quarter dummies to remove seasonality. For the Non-US Aggregate, consumption, investment, and government expenditures are constructed by summing over all countries, except the United States. For each country and the Non-US Aggregate, the cyclical fluctuations are obtained by detrending the logarithms of consumption, investment, and government expenditures from the HP filter. 


\section{A.4 National Saving}

For each country, national saving is the current account plus investment. For the Non-US Aggregate, national saving is constructed by summing over all countries, except the United States. For each country and the Non-US Aggregate, the cyclical fluctuations are extracted by detrending the national saving to output ratio from the HP filter.

\section{A.5 Technology}

For each country, technology is constructed from the production function (2.2) using the parametrization $\alpha=0.36$ for the capital share, and measures of output, capital, and employment. Capital is computed from the capital accumulation (1.3), the parametrizations $\delta=0.025$ for the depreciation rate and $\phi=3.20$ for the adjustment-cost parameter, the steady-state value of capital (for the initial period), and investment. Employment is calculated as the civilian-employment index for the baseyear 1995 (source: MEI) times the population in 1985 (source: Summers and Heston 1988, variable 1, Table 3). For the Non-US Aggregate, technology is constructed similarly using the Non-US Aggregate measures of output, investment, and employment. The Non-US Aggregate's employment is constructed by summing weighted employment over all countries except the United States, where the weights reflect each country's share of the Non-US Aggregate total population. For each country and the Non-US Aggregate, the cyclical fluctuations are obtained by detrending the logarithm of technology from the HP filter. 


\section{References}

Backus, D.K., P.J. Kehoe, and F.E. Kydland (1995), "International Business Cycles: Theory and Evidence," in T.F. Cooley (ed.), Frontiers of Business Cycle Research, Princeton: Princeton University Press.

Backus, D.K., P.J. Kehoe, and F.E. Kydland (1994), "Dynamics of the Trade Balance and the Terms of Trade: The J-curve?" American Economic Review 84, pp. $84-103$.

Backus, D.K., P.J. Kehoe, and F.E. Kydland (1992), "International Real Business Cycles, Journal of Political Economy 101, pp. 745-775.

Baxter, M. and M.J. Crucini (1995), "Business Cycles and the Asset Structure of Foreign Trade," International Economic Review 36, pp. 821-854.

Baxter, M. and M.J. Crucini (1993), "Explaining Saving-Investment Correlations," American Economic Review 83, pp. 416-436.

Boileau, M. and M. Normandin (2005), "Closing International Real Business Cycle Models with Restricted Financial Markets," Journal of International Money and Finance, Revise-Resubmit.

Boileau, M. and M. Normandin (2004), "Dynamics of the Current Account and Interest Differentials," Journal of International Economics, Revise-Resubmit.

Correia, I., J.C. Neves, and S.T. Rebelo (1995), "Business Cycles in a Small Open Economy," European Economic Review 39, pp. 1089-1113.

Devereux, M.B., A.W. Gregory, and G.W. Smith (1992), "Realistic Cross-Country Consumption Correlations in a Two-Country, Equilibrium, Business Cycle Model," Journal of International Money and Finance 11, pp. 3-16.

Elliott, G. and A. Fatas (1996), "International Business Cycles and the Dynamics of the Current Account," European Economic Review 40, pp. 361-387.

Glick, R. and K. Rogoff (1995), "Global versus Country-Specific Productivity Shocks and the Current Account," Journal of Monetary Economics 35, pp. 159-192. 
Greenwood, J., Z. Hercowitz, and G.W. Huffman (1988), "Investment, Capacity Utilization, and the Business Cycle," American Economic Review 78, pp. 401-417.

Gregory, A.W. and A.C. Head (1999), "Common and Country-Specific Fluctuations in Productivity, Investment, and the Current Account," Journal of Monetary Economics 44, pp. 423-451.

Hercowitz, Z. and M. Strawczynski (2004), "Cyclical Ratcheting in Government Spending: Evidence from the OECD," Review of Economics and Statistics 86, pp. 353-361.

Hodrick, R.J. and E.C. Prescott (1997), "Postwar U.S. Business Cycles: An Empirical Investigation," Journal of Money, Credit, and Banking 29, pp. 1-16.

Hoffmann, M. (2003), "International Macroeconomic Fluctuations and the Current Account," Canadian Journal of Economics 36, pp. 401-420.

Hoffmann, M. (2001), "The Relative Dynamics of Investment and the Current Account in the G7-Economies," Economic Journal 111, pp. 148-163.

Iscan, T.B. (2000), "The Terms of Trade, Productivity Growth, and the Current Account," Journal of Monetary Economics 45, pp. 587-611.

King, R.G., C.I. Plosser, and S.T. Rebelo (2002), "Production, Growth and Business Cycles: Technical Appendix," Computational Economics 20, pp. 87-116.

Lane, P.R. and G.M. Milesi-Ferretti (2002), "Long Term Capital Movements," in B.S. Bernanke and K. Rogoff (eds.), NBER Macroeconomics Annual 2001, Cambridge: MIT Press.

Nason, J.M. and J.H. Rogers (2002a), "The Present-Value Model of the Current Account Has Been Rejected: Round Up the Usual Suspects," Journal of International Economics, forthcoming.

Nason, J.M. and J.H. Rogers (2002b), "Investment and the Current Account in the Short Run and the Long Run," Journal of Money, Credit, and Banking 34, pp. 967-986.

Perotti, Roberto (2004), "Estimating the Effects of Fiscal Policy in OECD Countries," IGIER Working Paper. 
Sentana, E. (2004), "Factor Representing Portfolios in Large Asset Markets," Journal of Econometrics 119, pp. 257-289.

Summers, R. and A. Heston (1998), "A New Set of International Comparisons of Real Product and Price Level: Estimates for 130 Countries, 1950-1985, " Review of Income and Wealth 34, pp. 1-25. 
Table 1. Statistics: Baseline

\begin{tabular}{|c|c|c|c|c|c|c|c|c|c|}
\hline & \multicolumn{3}{|c|}{$\begin{array}{l}\text { Relative } \\
\text { Volatility }\end{array}$} & \multicolumn{4}{|c|}{$\begin{array}{l}\text { Within-Country } \\
\text { Correlation }\end{array}$} & \multicolumn{2}{|c|}{$\begin{array}{c}\text { Cross-Country } \\
\text { Correlation }\end{array}$} \\
\hline & $c$ & $i$ & $x$ & $(c, y)$ & $(i, y)$ & $(x, y)$ & $(s / y, i / y)$ & $\left(c, c^{*}\right)$ & $\left(y, y^{*}\right)$ \\
\hline Predicted & 0.94 & 2.32 & 0.25 & 0.98 & 0.87 & -0.28 & 0.71 & 0.32 & 0.28 \\
\hline United States & $\begin{array}{c}0.88 \\
(0.03)\end{array}$ & $\begin{array}{c}2.32 \\
(0.99)\end{array}$ & $\begin{array}{c}0.30 \\
(0.73)\end{array}$ & $\begin{array}{c}0.91 \\
(0.03)\end{array}$ & $\begin{array}{c}0.92 \\
(0.59)\end{array}$ & $\begin{array}{l}-0.48 \\
(0.02)\end{array}$ & $\begin{array}{c}0.43 \\
(0.04)\end{array}$ & & \\
\hline Non-US Aggregate & $\begin{array}{c}0.85 \\
(0.01)\end{array}$ & $\begin{array}{c}2.62 \\
(0.47)\end{array}$ & $\begin{array}{c}0.49 \\
(0.11)\end{array}$ & $\begin{array}{c}0.87 \\
(0.01)\end{array}$ & $\begin{array}{c}0.79 \\
(0.24)\end{array}$ & $\begin{array}{l}-0.28 \\
(0.93)\end{array}$ & $\begin{array}{c}0.39 \\
(0.02)\end{array}$ & $\begin{array}{c}0.20 \\
(0.70)\end{array}$ & $\begin{array}{c}0.38 \\
(0.73)\end{array}$ \\
\hline 10-Country Average & $\begin{array}{c}0.90 \\
(0.11)\end{array}$ & $\begin{array}{c}2.59 \\
(0.52)\end{array}$ & $\begin{array}{c}0.62 \\
(0.02)\end{array}$ & $\begin{array}{c}0.79 \\
(0.00)\end{array}$ & $\begin{array}{c}0.74 \\
(0.07)\end{array}$ & $\begin{array}{l}-0.25 \\
(0.51)\end{array}$ & $\begin{array}{c}0.30 \\
(0.00)\end{array}$ & $\begin{array}{c}0.17 \\
(0.63)\end{array}$ & $\begin{array}{c}0.29 \\
(0.98)\end{array}$ \\
\hline
\end{tabular}

Note: Entries under relative volatility, within-country correlation, and cross-country correlation refer to the predicted and sample standard deviations of the variable relative to the predicted and sample standard deviations of $y$, the predicted and sample contemporaneous correlations between domestic variables, and the predicted and sample contemporaneous correlations between domestic and foreign variables. The variables are the logarithm of output $(y)$, the logarithm of consumption $(c)$, the logarithm of investment $(i)$, the ratio of the current account to output $(x)$, the rate of national saving $(s / y)$, and the rate of investment $(i / y)$. The predicted statistics are constructed from the baseline parametrization, which includes all shocks. The statistics for the United States, the Non-US Aggregate, and the 10-Country Average are computed by detrending the variables from the HP filter. The Non-US Aggregate is an aggregate of the 10 countries, except the United States. The 10-Country Average is the mean statistic over all 10 countries for the relative volatility and within-country correlation, and the average of all the bilateral statistics for the cross-country correlation. Entries in parentheses are the $p$-values from a $\chi^{2}(1)$ distributed test that the difference between the predicted and empirical statistics is null. The test uses the variance of the difference, which is computed as $\mathbf{D}^{\prime} \boldsymbol{\Xi D}$ - where $\mathbf{D}$ is the vector of numerical derivatives of the difference with respect to the estimated parameters $(\boldsymbol{\Theta}$ and $\boldsymbol{\Omega})$ of the exogenous-variable process (6), and $\boldsymbol{\Xi}$ is the covariance matrix of these estimates. 
Table 2. Statistics: Global Shocks

\begin{tabular}{|c|c|c|c|c|c|c|c|c|c|}
\hline & \multicolumn{3}{|c|}{$\begin{array}{l}\text { Relative } \\
\text { Volatility }\end{array}$} & \multicolumn{4}{|c|}{$\begin{array}{l}\text { Within-Country } \\
\text { Correlation }\end{array}$} & \multicolumn{2}{|c|}{$\begin{array}{c}\text { Cross-Country } \\
\text { Correlation }\end{array}$} \\
\hline & $c$ & $i$ & $x$ & $(c, y)$ & $(i, y)$ & $(x, y)$ & $(s / y, i / y)$ & $\left(c, c^{*}\right)$ & $\left(y, y^{*}\right)$ \\
\hline Baseline & 0.94 & 2.32 & 0.25 & 0.98 & 0.87 & -0.28 & 0.71 & 0.32 & 0.28 \\
\hline Technology & 0.98 & 1.70 & 0.00 & 0.99 & 0.98 & - & 1.00 & 1.00 & 1.00 \\
\hline Gvt Expenditures & 1.28 & 3.63 & 0.00 & 0.97 & 0.46 & - & 1.00 & 1.00 & 1.00 \\
\hline
\end{tabular}

Note: Entries under relative volatility, within-country correlation, and cross-country correlation refer to the predicted standard deviation of the variable relative to the predicted standard deviation of $y$, the predicted contemporaneous correlation between domestic variables, and the predicted contemporaneous correlation between domestic and foreign variables. - indicates that the correlation is not defined because the standard deviation of one of the involved variables is null. The variables are the logarithm of output $(y)$, the logarithm of consumption $(c)$, the logarithm of investment $(i)$, the ratio of the current account to output $(x)$, the rate of national saving $(s / y)$, and the rate of investment $(i / y)$. Baseline refers to the baseline parametrization, which includes all shocks. Technology refers to the alternative parametrization which includes only global technology shocks. Government expenditures refer to the alternative parametrization which includes only global government-expenditure shocks. 
Table 3. Variance Decompositions: Global Shocks

\begin{tabular}{|c|c|c|c|}
\hline Variables & $h$ & Technology & Gvt Expenditures \\
\hline \multirow[t]{3}{*}{$y$} & 1 & 24.62 & 0.00 \\
\hline & 5 & 27.36 & 0.00 \\
\hline & 10 & 28.64 & 0.00 \\
\hline \multirow[t]{3}{*}{$c$} & 1 & 26.14 & 0.00 \\
\hline & 5 & 29.30 & 0.00 \\
\hline & 10 & 31.00 & 0.01 \\
\hline \multirow[t]{3}{*}{$i$} & 1 & 9.45 & 0.02 \\
\hline & 5 & 12.93 & 0.02 \\
\hline & 10 & 14.78 & 0.02 \\
\hline \multirow[t]{3}{*}{$x$} & 1 & 0.00 & 0.00 \\
\hline & 5 & 0.00 & 0.00 \\
\hline & 10 & 0.00 & 0.00 \\
\hline
\end{tabular}

Note: Entries are the contributions (in percent) of each global shock to the variances of $h$-quarter-ahead forecast errors of the variables. The variables are the logarithm of output $(y)$, the logarithm of consumption $(c)$, the logarithm of investment $(i)$, and the ratio of the current account to output $(x)$. 


\section{Table 4. Statistics: Country-Specific Shocks}

\begin{tabular}{|c|c|c|c|c|c|c|c|c|c|}
\hline & \multicolumn{3}{|c|}{$\begin{array}{l}\text { Relative } \\
\text { Volatility }\end{array}$} & \multicolumn{4}{|c|}{$\begin{array}{l}\text { Within-Country } \\
\text { Correlation }\end{array}$} & \multicolumn{2}{|c|}{$\begin{array}{c}\text { Cross-Country } \\
\text { Correlation }\end{array}$} \\
\hline & $c$ & $i$ & $x$ & $(c, y)$ & $(i, y)$ & $(x, y)$ & $(s / y, i / y)$ & $\left(c, c^{*}\right)$ & $\left(y, y^{*}\right)$ \\
\hline Baseline & 0.94 & 2.32 & 0.25 & 0.98 & 0.87 & -0.28 & 0.71 & 0.32 & 0.28 \\
\hline \multicolumn{10}{|l|}{ Technology } \\
\hline Country-Specific & 0.93 & 2.56 & 0.30 & 0.98 & 0.87 & -0.33 & 0.71 & -0.03 & -0.05 \\
\hline Domestic & 0.93 & 2.43 & 0.21 & 0.99 & 0.92 & -0.48 & 0.82 & -0.34 & -0.36 \\
\hline Foreign & 0.62 & 12.67 & 3.26 & 0.88 & 0.06 & 0.12 & -0.02 & -0.34 & -0.36 \\
\hline \multicolumn{10}{|l|}{ Gvt Expenditures } \\
\hline Country-Specific & 1.34 & 3.64 & 0.08 & 0.97 & 0.46 & -0.32 & 0.99 & 0.08 & 0.18 \\
\hline Domestic & 1.34 & 3.65 & 0.60 & 0.97 & 0.46 & -0.50 & 0.99 & 0.57 & 0.85 \\
\hline Foreign & 0.85 & 3.28 & 0.55 & 0.85 & 0.44 & 0.46 & 0.98 & 0.57 & 0.85 \\
\hline
\end{tabular}

Note: Entries under relative volatility, within-country correlation, and cross-country correlation refer to the predicted standard deviation of the variable relative to the predicted standard deviation of $y$, the predicted contemporaneous correlation between domestic variables, and the predicted contemporaneous correlation between domestic and foreign variables. The variables are the logarithm of output $(y)$, the logarithm of consumption $(c)$, the logarithm of investment $(i)$, the ratio of the current account to output $(x)$, the rate of national saving $(s / y)$, and the rate of investment $(i / y)$. Baseline refers to the baseline parametrization, which includes all shocks. Technology refers to the alternative parametrizations which include either country-specific (i.e. domestic and foreign) technology shocks, domestic technology shocks, or foreign technology shocks. Government expenditures refer to the alternative parametrizations which include either country-specific (i.e. domestic and foreign) government-expenditure shocks, domestic governmentexpenditure shocks, or foreign government-expenditure shocks. 
Table 5. Variance Decompositions: Country-Specific Shocks

\begin{tabular}{|c|c|c|c|c|c|}
\hline \multirow[t]{2}{*}{ Variables } & \multirow[t]{2}{*}{$h$} & \multicolumn{2}{|c|}{ Technology } & \multicolumn{2}{|c|}{ Gvt Expenditures } \\
\hline & & Domestic & Foreign & Domestic & Foreign \\
\hline \multirow[t]{3}{*}{$y$} & 1 & 75.38 & 0.00 & 0.00 & 0.00 \\
\hline & 5 & 72.53 & 0.10 & 0.01 & 0.00 \\
\hline & 10 & 71.01 & 0.22 & 0.03 & 0.00 \\
\hline \multirow[t]{3}{*}{$c$} & 1 & 73.75 & 0.01 & 0.10 & 0.00 \\
\hline & 5 & 70.50 & 0.06 & 0.14 & 0.00 \\
\hline & 10 & 68.70 & 0.09 & 0.20 & 0.00 \\
\hline \multirow[t]{3}{*}{$i$} & 1 & 79.36 & 10.49 & 0.67 & 0.01 \\
\hline & 5 & 77.94 & 8.35 & 0.75 & 0.01 \\
\hline & 10 & 76.29 & 8.12 & 0.78 & 0.01 \\
\hline \multirow[t]{3}{*}{$x$} & 1 & 49.99 & 49.99 & 0.01 & 0.01 \\
\hline & 5 & 49.98 & 49.98 & 0.02 & 0.02 \\
\hline & 10 & 49.98 & 49.98 & 0.02 & 0.02 \\
\hline
\end{tabular}

Note: Entries are the contributions (in percent) of each country-specific shock to the variances of $h$-quarter-ahead forecast errors of the variables. The variables are the logarithm of output $(y)$, the logarithm of consumption $(c)$, the logarithm of investment $(i)$, and the ratio of the current account to output $(x)$. 


\section{Figure 1. Global and Country-Specific Components: Estimates}
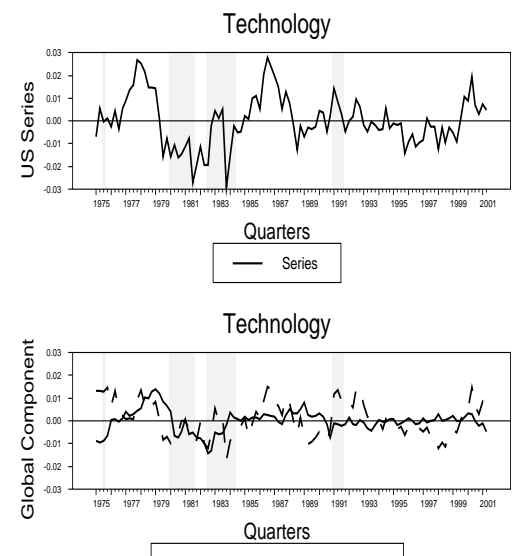

Q Kalman - Average
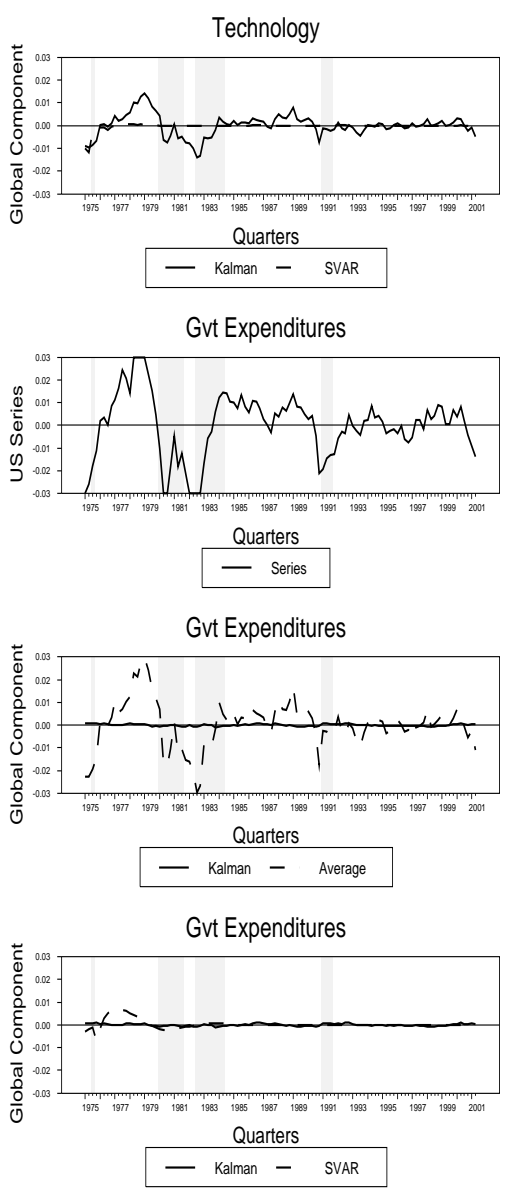
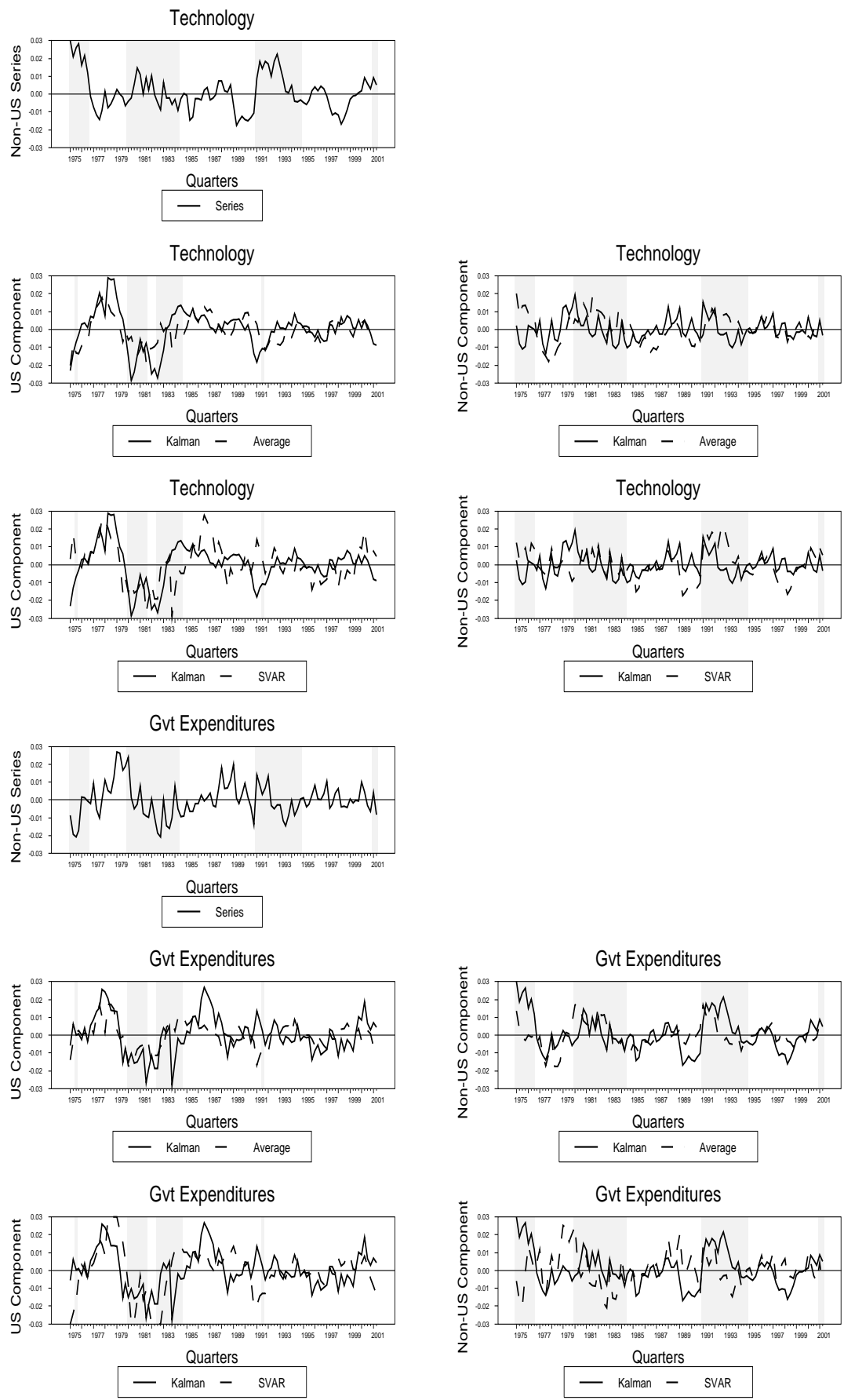

Note: The shaded boxes represent contractionary phases (i.e. peaks to troughs). For the global components, the contractionary phases correspond to periods where the United States and Germany are simultaneously in contractionary phases. For the US components, the contractionary phases are those reported for the United States by the National Bureau of Economic Research (NBER). For the non-US components, the contractionary phases are those reported for Germany by the Economic Cycle Research Institute (ECRI) (www.businesscycle.com). The ECRI applies the same method than the one used by the NBER. 


\section{Figure 2. Dynamic Responses: Global Shocks}
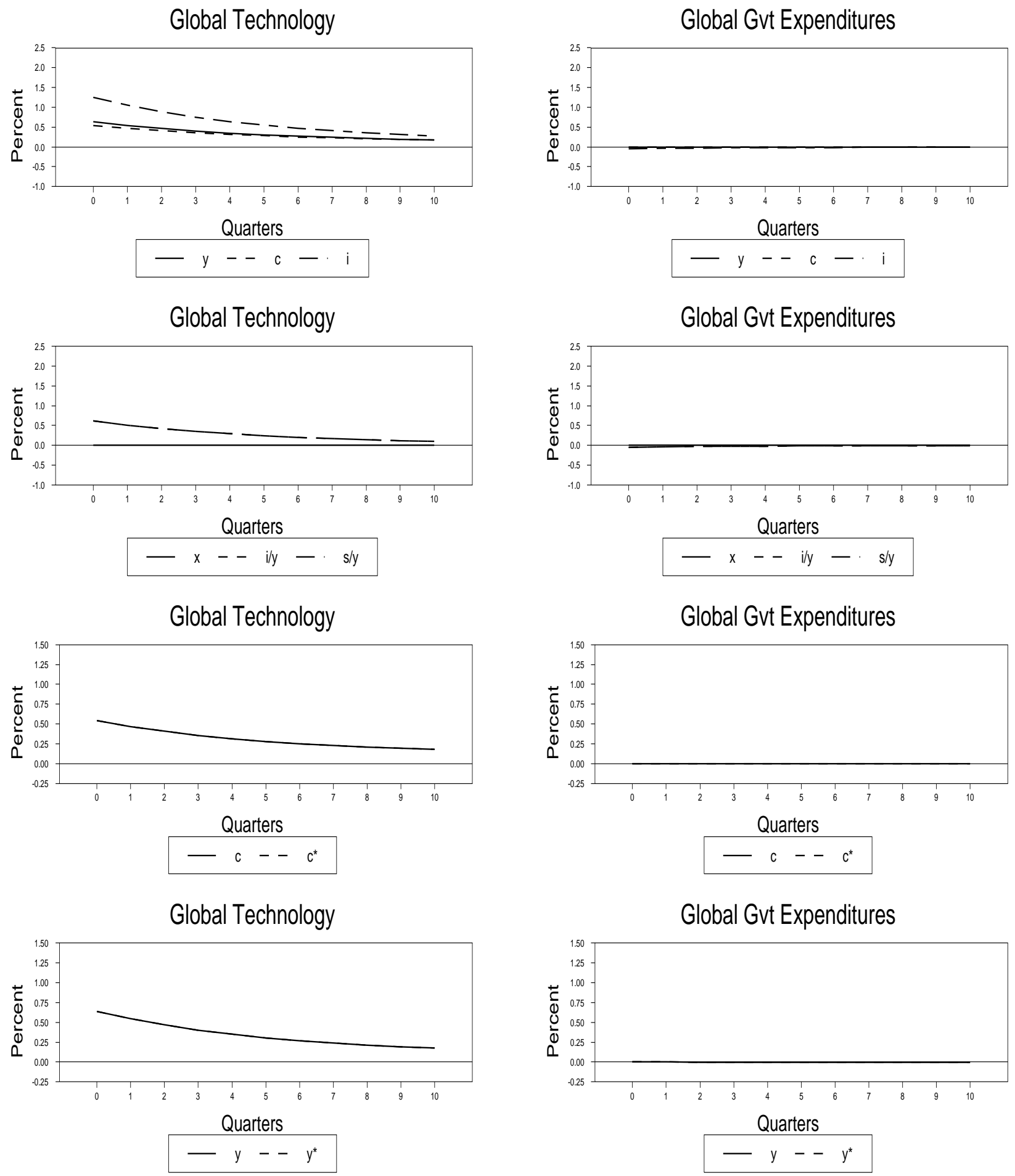


\section{Figure 3. Dynamic Responses: Country-Specific Technology Shocks}
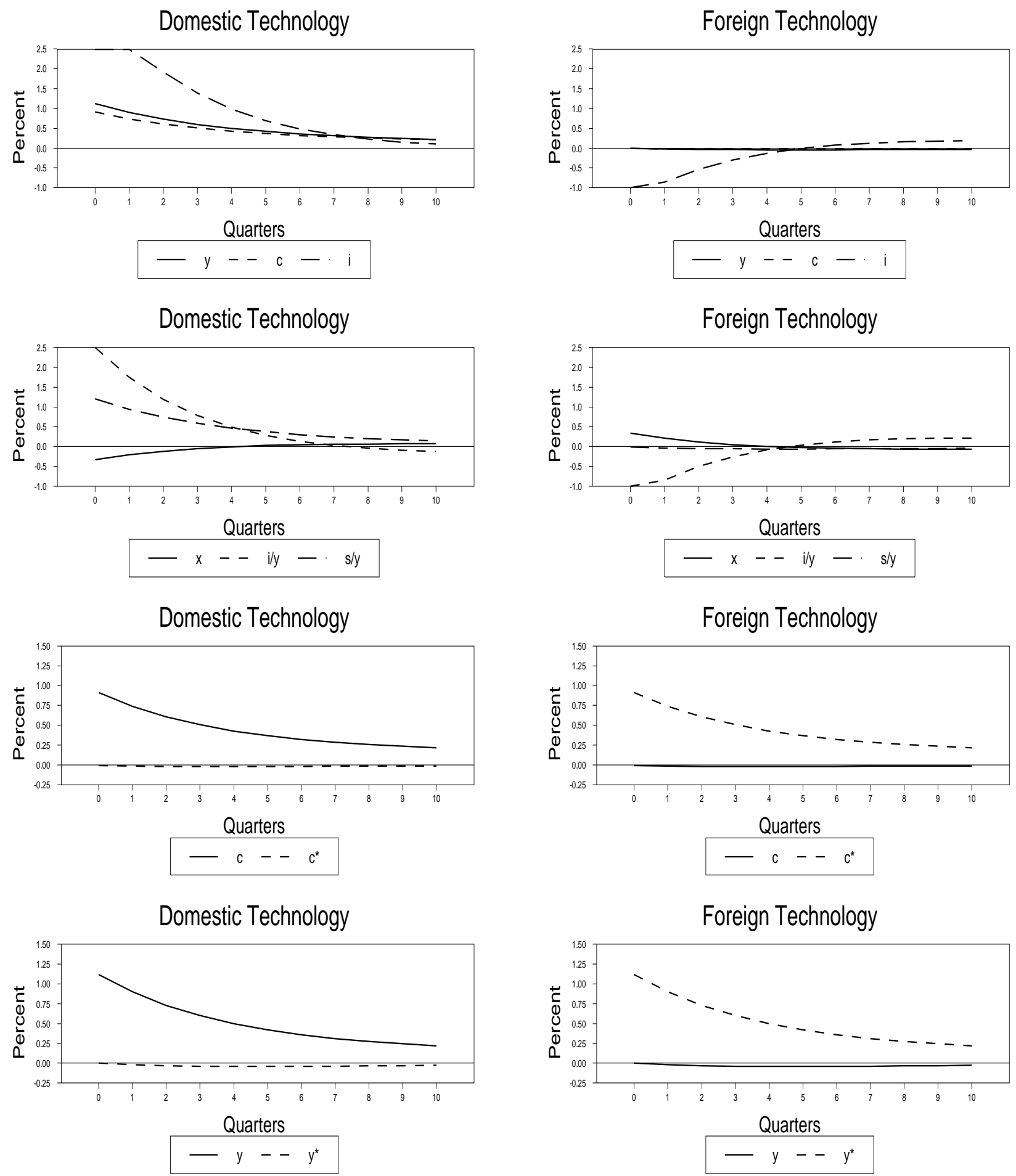
Figure 4. Dynamic Responses: Country-Specific Government-Expenditure Shocks
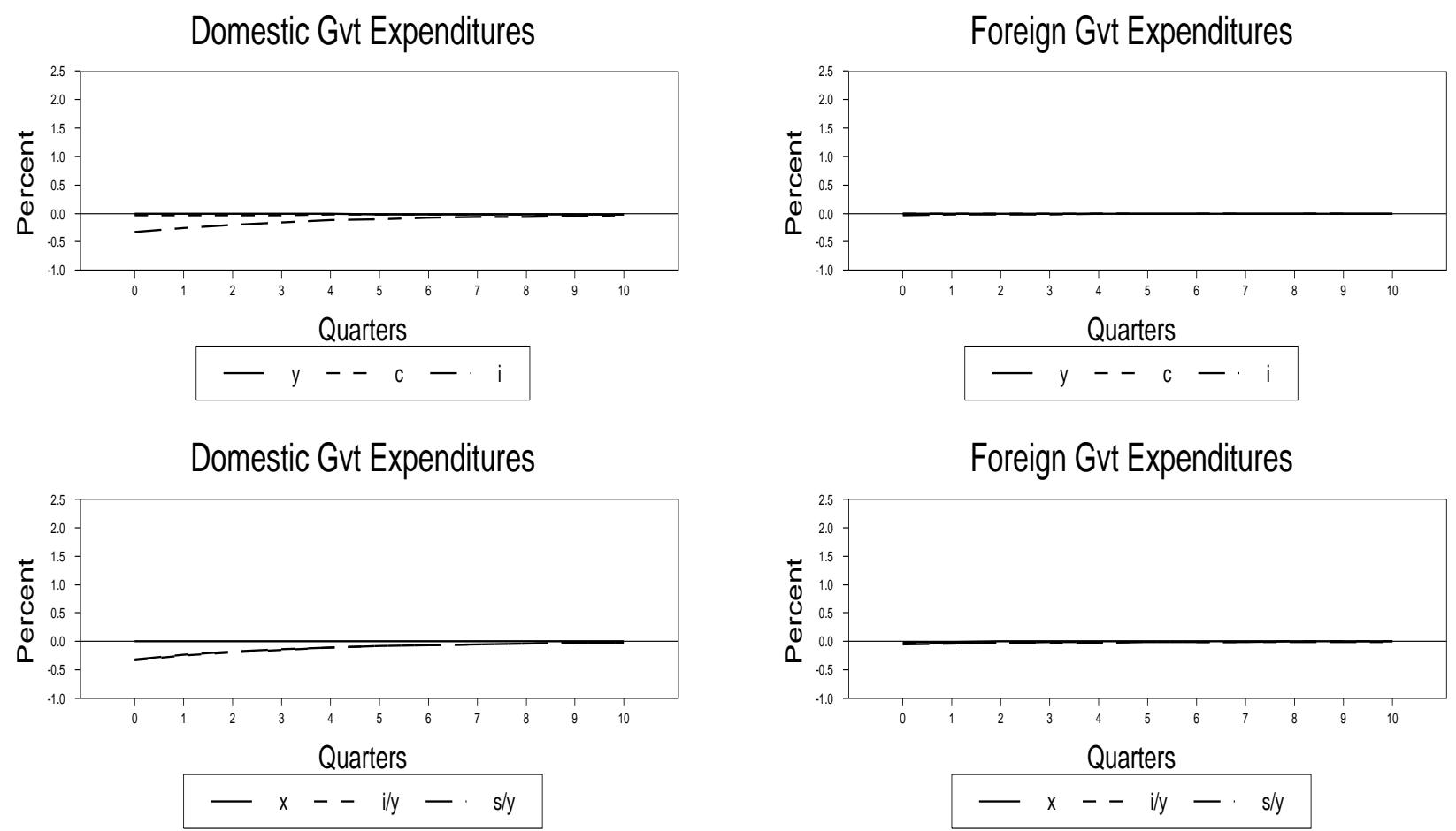

Domestic Gvt Expenditures

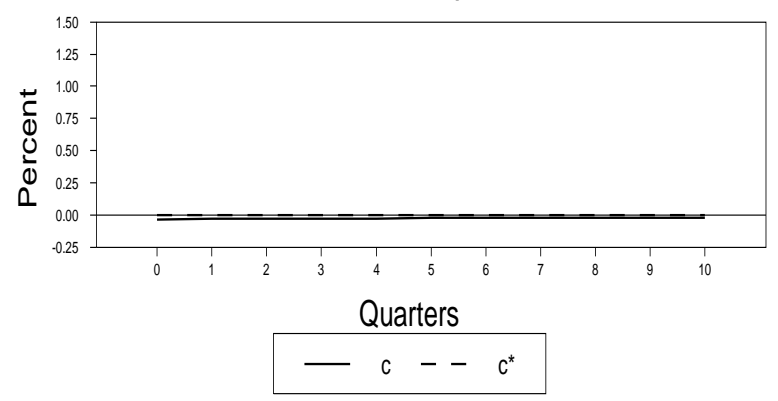

Domestic Gvt Expenditures
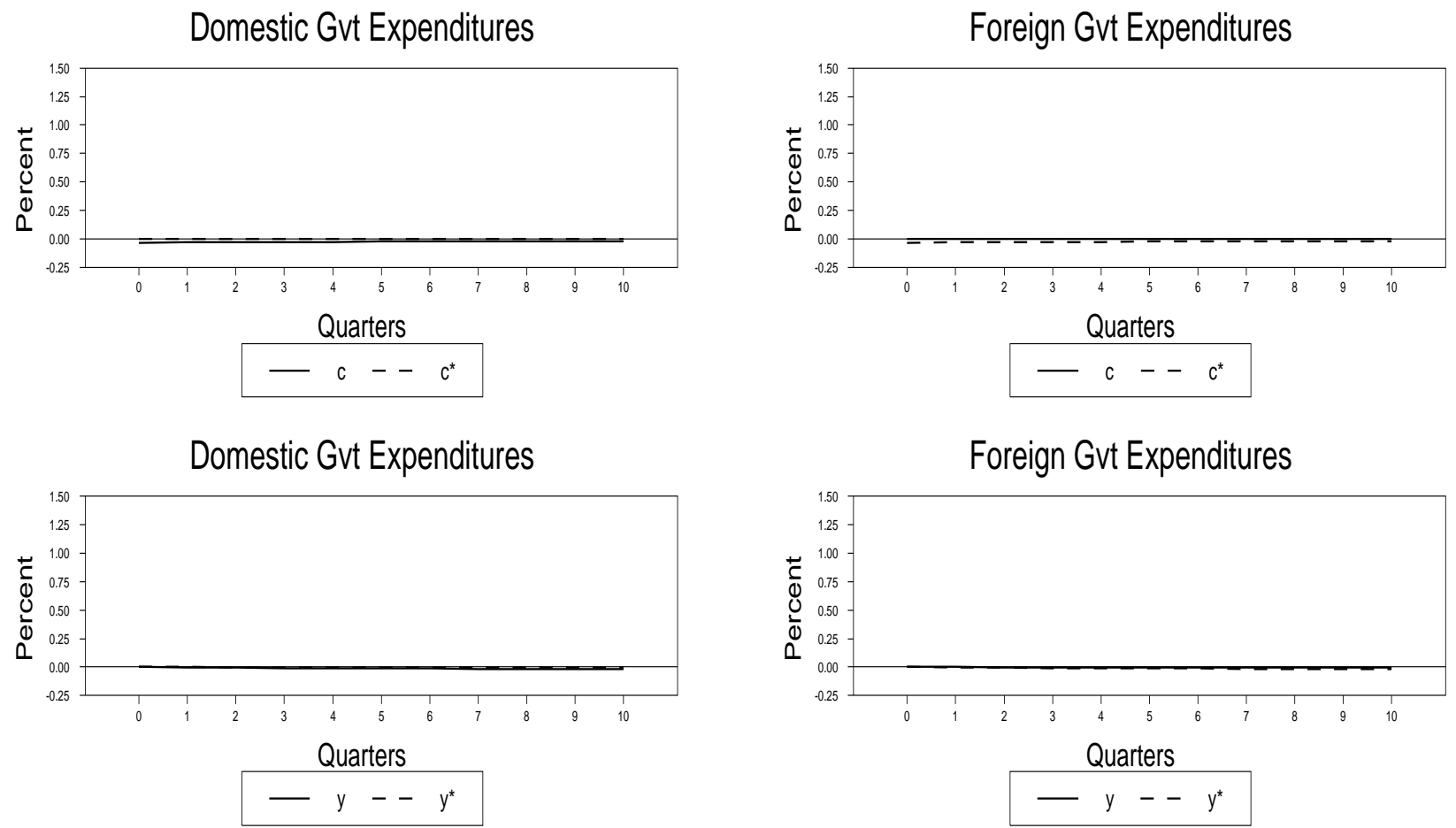


\section{Liste des cahiers de recherche publiés par les professeurs des H.E.C. 2004-2005}

\section{Institut d'économie appliquée}

IEA-04-01: LEACH, ANDREW. «Integrated Assessment of Climate Change Using an OLG Model », 34 pages.

IEA-04-02: LEACH, ANDREW. " SubGame, set and match. Identifying Incentive Response in a Tournament », 39 pages.

IEA-04-03: LEACH, ANDREW. « The Climate Change Learning Curve », 27 pages.

IEA-04-04: DOSTIE, BENOIT; VENCATACHELLUM, DÉSIRÉ. « Compulsory and Voluntary Remittances: Evidence from Child Domestic Workers in Tunisia », 46 pages.

IEA-04-05: RENGIFo, E.W.; ROMBOUTS, J.V.K. « Dynamic Optimal Portfolio in a VaR Framework », 33 pages.

IEA-04-06: DOSTIE, BENOIT; TRÉPANIER, MATHIEU. « Return to Computer Use and Organizational Practices of the Firm », 41 pages.

IEA-04-07: ALLARD, MARIE; LÉGER, PIERRE THOMAS; ROCHAIX, LISE. « Provider Competition in a Dynamic Setting » 32 pages

IEA-04-08: MAURICE N. MARCHON. «Perspectives économiques canadiennes dans un contexte international » 27 pages.

IEA-04-09: NORMANDIN, MICHEL. " The Current Account and the Interest Differential in Canada », 27 pages.

IEA-04-10 AZAM, JEAN-PAUL; GAUTHIER, BERNARD; GOYETTE, JONATHAN. « The Effect of Fiscal Policy and Corruption Control Mechanisms on Firm Growth and Social Welfare: Theory and Evidence », 50 pages.

IEA-04-11 RUTH DUPRÉ. «The Prohibition of Alcohol Revisited : the US Case in International Perspective », 28 pages.

IEA-04-12 BÉlAIR, MARJOLAINE; GAUTHIER, BERNARD. «Les effets de l'immigration sur le commerce bilatéral : le cas de l’Australie et des pays de l’Asie du Sud-Est », 50 pages. 
IEA-04-13 LAROCQUe, DENIS; NORMANDIN, MICHEL. «Econometric Inference, Cyclical Fluctuations, and Superior Information », 40 pages.

IEA-04-14 ROMBOUTS, JEROEN V.K.; VERBEEK MARNO. « Evaluating Portfolio Value-at-Risk Using Semi-parametric Garch Models », 30 pages.

IEA-05-01 DÉSIRÉ VENCATACHALLUM ET BRUNO VERSAEVEL. « R\&D Delegation in a Duopoly with Spillovers », 57 pages.

IEA-05-02 MiCHEL NORMANDin ET PASCAL St-AMOUR.. « An Empirical Analysis of U.S. Aggregate Portfolio Allocations », 33 pages.

IEA-05-03 MARTIN BOILEAU ET MiCHEL NORMANDIN. « Closing International Real Business Cycle Models with Restricted Financial Markets », 36 pages.

IEA-05-04 GEORGES DIONNE ET BENOIT DOSTIE. «New Evidence on the Determinants of Absenteeism Using Linked Employer-Employee Data », 35 pages.

IEA-05-05 MAURICE N. MARCHON. «Perspectives économiques canadiennes dans un contexte international », 27 pages. 